\title{
A CONTRIBUIÇÃO DO RIO FIÚZA NO CONTEXTO CULTURAL PAISAGÍSTICO
}

\author{
Cléa Hempe ${ }^{1}$, Alberto Yates Moroni ${ }^{2}$, Juliane Stenzinger Bergamim ${ }^{3}$, Cristiomar Golo ${ }^{4}$ \\ ${ }^{1}$ Professora de Geografia. Atua no Museu Arquivo Histórico Professor Hermann Wegermann como professora \\ pesquisadora. Mestranda em Geografia na UFSM: cleahempe@yahoo.com.br, \\ 2 albertoyatesmoroni@yahoo.com.br, ${ }^{3}$ ju_sten@hotmail.com, ${ }^{4}$ cristiomargolo@hotmail.com
}

\section{RESUMO}

O estudo atual da paisagem adquire elementos naturais e humanos, em uma pluralidade nunca antes trabalhada. Nesse contexto, a bacia hidrográfica do rio Fiúza adquire aspectos multifuncionais, como espaço usado e vivenciado pela população de Panambi. Um exemplo disso em espaço panambiense é o Parque Municipal Rudolfo Arno Goldhardt. Desta forma, procura-se a realização por meio de abordagem analítica proposta na transformação paisagística da bacia hidrográfica do rio Fiúza, mais especificamente de alguns pontos compreendidos na área urbana do município de Panambi. Neste sentido, torna-se necessário a contextualização das especificidades das diversas formas de utilização do rio Fiúza, discorrendo assim, sobre a valoração da paisagem em seu âmbito local, juntamente correlacionados com os resultados obtidos.

Palavras-chave: Multifuncionalidade da Paisagem. Paisagem. Paisagem Cultural. Panambi. Rio Fiúza. Trilhas ecológicas.

\begin{abstract}
The current study of the Landscape acquires natural and human elements in a plurality never worked before. In this context, The Fiuza river basin acquires multifunctional aspects, such as the space, that is used and experienced by the population of Panambi. An example of this is Rudolfo Arno Goldhardt Municipal Park. Thus, the aim is the realization by means of analytical approach proposed in the transformation of landscape of the Fiuza river basin, more specifically of some items on the urban area in Panambi. In this sense, it is necessary to contextualize the particularities of the numerous uses of the Fiuza river, discoursing so, on the valuation of the local landscape, also correlated with the obtained results.
\end{abstract}

Keywords: Multifunctionality of Landscape. Landscape. Cultural Landscape. Panambi. Rio Fiuza. Nature trails. 
“No traçado das estradas, como nos estabelecimentos de arraiais e povoações, o problema da água desempenhou quase sempre papel de importância primordial".

Sérgio Buarque de Holanda

\section{INTRODUÇÃO}

Os seres humanos, por meio de suas relações sociais, premissas culturais vem alterando ao longo da história seu meio ambiente circundante. Estas reconfigurações e aspirações na estrutura social, política e econômica tem como fator endêmico o meio ambiente.

Neste sentido, é discutido e problematizado debates por meio de várias academias, esta vivência dos seres humanos em 'conformidade' com seu meio ambiente. Conformidade esta, que é relacionada necessariamente não com seu uso, mas sim com sua coexistência.

O meio ambiente e sua preservação/conservação estão intimamente ligados à sobrevivência do homem enquanto espécie, porém o caráter dominador e explorador do qual se investe o ser humano está relegando ao segundo plano estas questões, por isso, a natureza vai se tornando indefesa, vítima do progresso econômico e industrial da humanidade.

O propósito deste artigo é abranger discussões a cerca dos contextos culturais inseridos na paisagem de Panambi/RS. Neste sentido, considera-se imprescindível problematizar sobre a importância e as facetas que os recursos hídricos abrangem nesta área, juntamente com a importância intrínseca da paisagem, assim como sua multifuncionalidade.

O município abrange uma área de $409,9 \mathrm{~km}^{2}$ e localiza-se no Planalto Médio Gaúcho, região Noroeste Colonial do Estado do Rio Grande do Sul. Está situado nas coordenadas geográficas 2817'33" de latitude sul e 5330'06" de longitude oeste, a $418 \mathrm{~m}$ de altitude, como mostra a Figura 1- Mapas: Rio Grande do Sul/Panambi e Zona Urbana do município de Panambi/RS. 

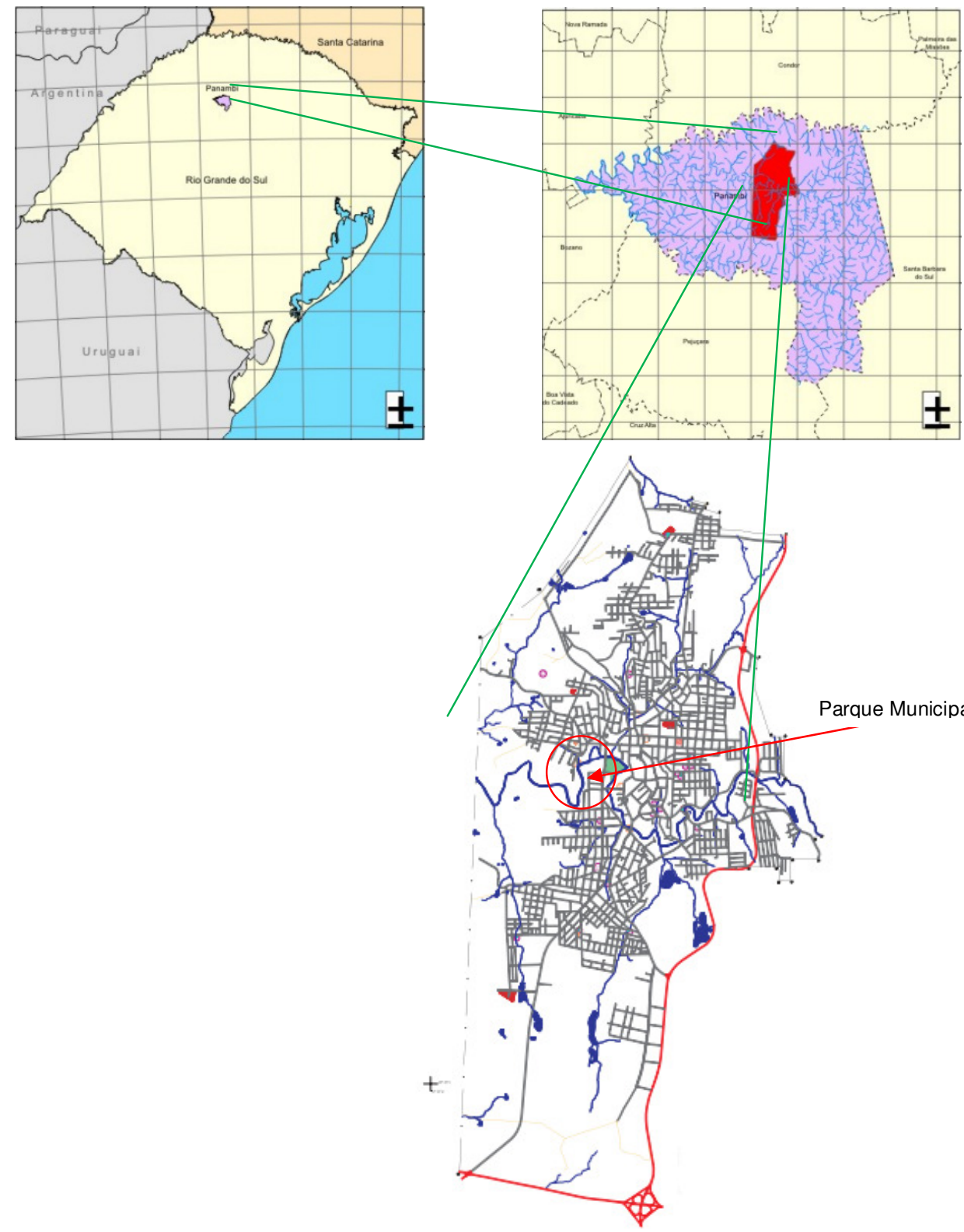

Parque Municipal Rudolfo Arno Goldhardt

Figura 1 - Mapas: Rio Grande do Sul/Panambi e Zona Urbana de Panambi/RS. Fonte: PANAMBI. Plano Diretor, 2006; Plano de Saneamento Básico, 2008.

A sede municipal encontra-se situada numa posição estratégica, pois nela estão o entroncamento de duas das principais rodovias federais do Estado, as BR's 158 e 285, que ligam o Estado de norte a sul, leste a oeste. Tem como limites os municípios de Condor ao norte; Santa Bárbara do Sul a leste; Ajuricaba a noroeste; Bozano a oeste e Pejuçara ao sul. Segundo o IBGE (2010), o município de Panambi concentra 92,8\% de sua população na zona urbana.

O objetivo geral deste artigo consiste em realizar uma abordagem de forma analítica da transformação paisagística da bacia hidrográfica do rio Fiúza, mais especificamente de alguns 
pontos compreendidos na área urbana do município de Panambi, a partir dos referenciais teóricos disponibilizados na disciplina de Tópicos Especiais em Geografia e, buscando ainda, materiais em outras fontes, a fim de enriquecer esta abordagem. Traz como objetivos específicos: analisar a paisagem do Parque Municipal Rudolfo Arno Goldhardt; pesquisar e contextualizar as especificidades das diversas formas de utilização do rio Fiúza ao longo do século XX até aos dias atuais e, discorrer sobre a valoração da paisagem do Parque Municipal em seu âmbito local e sua relação com o rio.

A metodologia consistiu na busca de materiais complementares, seleção de referenciais teóricos, levantamento de dados qualitativos e quantitativos, seleção de imagens relacionadas ao objeto de estudo, sistematização dos temas afins e, por fim, a elaboração do artigo científico.

\section{REFERENCIAL TEÓRICO}

\section{O processo de ocupação e sua relação com a paisagem}

A ausência de planejamento e a consequente destruição dos recursos naturais caracterizou o processo de ocupação do Brasil. Ao longo da história, a cobertura florestal nativa foi sendo fragmentada, cedendo espaço para os campos agricultáveis e também para as cidades. No que tange as áreas urbanas, o que se observa são pequenas áreas que respeitam as condicionantes físicas e hídricas naturais da região. Conforme afirma Radoll (2009) "a destruição da flora dos mananciais, o dejeto de efluentes diretamente nas águas dos rios, acaba por provocar o desinteresse da população ribeirinha pelo potencial paisagístico dos rios".

Cunha (2007) relata que ao longo da história da humanidade os rios têm sido utilizados como vias de penetração para o interior, facilitando o crescimento de aglomerados urbanos e, que em função da intensidade de uso no decorrer do tempo, vêm sofrendo efeitos e/ou impactos negativos no seu padrão natural.

Aguiar et. al (2008) relatam que dentre os ambientes naturais mais ameaçados e devastados pela ação antrópica estão os ambientes lacustres. Esse, por sua vez, é muito vulnerável a impactos externos, o que coloca em risco a fauna e a flora peculiar a este ambiente.

O processo de urbanização foi conseguindo, com o tempo, anular a importância dos rios dentro do cenário urbano. "As pessoas que trabalham, moram, circulam ou se divertem junto ao rio não percebem isto, mesmo quando induzidas a pensar" (OSEKI, 2000, p.174). Os rios são vistos pela população como problema, pois ocasionam enchentes, causam mau cheiro, são depósitos de lixos e esgoto a céu aberto e ainda, tornam-se obstáculos para circulação (GORSKI, 2008).

Diante deste cenário, muitos municípios acabam realizando ações no sentido de ocultar estes rios da paisagem urbana, canalizando-os, ao invés de adotar alternativas de adequações. Neste sentido, faz-se necessária uma reversão de valores, percebendo as pessoas como atores diretamente influentes na paisagem urbana, tornando espaços apropriados para o convivio humano, com grande potencial de criação de áreas verdes de preservação. Os rios, por terem muito a oferecer, além da água, possuem as paisagens fluviais, que podem ser apropriadas nos meios urbanos, tornando-se locais de lazer, circulação, convivência, entre outros.

Desta forma, é sabido que o ser humano se relaciona com o ambiente e com as outras pessoas através de estimulos que recebe. Esses, por sua vez, são originados do próprio ambiente. 
Estimulados a interagir, o ser humano se apropria de formas, cheiros, sons, sensações, volumes e outros, muitas vezes de forma inconsciente, mas que fazem com que o homem desenvolva sua personalidade.

Assim, ao longo da história, o ser humano têm buscado construir invólucros que possibilitem ou substituam as sensações naturais, tornando sua existência mais prazerosa. Atualmente, num mundo predominantemente urbano, o homem busca tornar os espaços em que convive mais adequados e sadios. Contudo, a grande maioria da população vive praticamente dentro de edifícios, sem um contato direto com o meio ambiente, tornando o termo 'natureza' objeto de cobiça entre os homens.

Desse modo, as sensações e estímulos que os habitantes de áreas urbanas experimentam em suas vidas são, em geral, idealizados e criados por si próprios, sendo produtos de sua intervenção com o meio natural (EMERY; RHEINGANTZ, 2011).

Com base nas sensações vividas pelos seres humanos, destaca-se a presença da arquitetura, presente na quase totalidade dos espaços ocupados pelos seres humanos. "O modo como o homem vê, ouve, cheira, degusta e sente é influenciado, em maior ou menor medida, pela arquitetura" (EMERY; RHEINGANTZ, 2011).

Assim, pode-se afirmar a influência que a arquitetura do ambiente causa nas pessoas. Um parque urbano, local dotado dos mais variados sentidos, sejam eles paisagisticos, culturais, sociais, entre outros, é um espaço propício para o desenvolvimento de atividades humanas em contato com a natureza. Neste sentido, Bonametti, nos diz:

\footnotetext{
a paisagem urbana é reflexo da relação entre o homem e a natureza, podendo ser interpretada como a tentativa de ordenamento do entorno com base em uma paisagem natural, e de uma cultura, a partir do modo como é projetada e construída, como resultado da observação do ambiente e da experiência individual ou coletiva com relação ao meio (2000, p.5).
}

Ainda segundo Sandeville (2005), "a paisagem, é mais do que espaço observado, trata-se de espaço vivenciado, da sensibilidade das pessoas com seu entorno". Assim, conceitua-se Paisagem Natural como aquela "resultante da interação dos fatores físicos e bióticos do meio ambiente, sem que tenha sido transformada sensivelmente pelas atividades humanas" (VEROCAI, 1990, p. 151). Já em relação à Paisagem Cultural, para a mesma autora, é definida como aquela resultante de intervenção antrópica, quer dizer, paisagem natural modificada por ação humana.

Os estudos sobre a Paisagem vêm adquirindo diferentes visões, segundo o contexto espaço-temporal em que se insere. Guimarães (2007, p. 11) diz que "durante a evolução do conceito de paisagem, observamos que as primeiras concepções expressavam uma preocupação essencialmente voltada à percepção dos aspectos e valores estéticos adotada pela arte, literatura e o paisagismo". Para a autora, essa visão dominou por milênios, principalmente entre os séculos XV e XVIII, quando se desenvolve na Europa as escolas de pintura.

Foi durante os séculos XVIII e XIX que o significado de Paisagem passou por transformações e começou a ser estudado pela Geografia, no sentido da compreensão da paisagem experienciada como uma realidade espacial/visual, no contexto dos estudos sobre o meio ambiente. Somente a partir do século XIX, o naturalista Alexander Von Humboldt, introduziu o significado científico-geográfico na concepção de paisagem, para definir a caracterização 
fisiográfica, geológica, geomorfológica, que marca o caráter total de uma região terrestre (GUIMARÃES, 2007).

A partir de meados do século XIX até meados do século XX, com a emergência de novos problemas espaciais, novas abordagens sobre a Paisagem surgiram. Vários estudos passaram a existir, abordando a Paisagem sob diferentes aspectos, sejam físicos e/ou humanos. Nesse período, que vai até meados do século $\mathrm{XX}$, ainda não se observava uma análise integrada das paisagens naturais e culturais. Para Guimarães (2007, p. 11), foi no período compreendido entre as guerras que vários questionamentos ganharam ênfase, conforme afirma:

[...] durante as décadas anteriores e posteriores ao período compreendido pelas duas guerras mundiais e, de forma especial, nos primeiros anos subsequentes ao pós-guerra de 1945, as questões geopolíticas relativas à reorganização das fronteiras internacionais, rupturas de relações colonialistas, estabelecimentos de acordos colaboracionistas e mercantis, problemas e conflitos relacionados à poluição e qualidade ambiental, conduziram a diversos questionamentos sobre a paisagem.

Desta maneira, houve um rompimento com a visão cartesiana da paisagem, inaugurando uma visão holística de sua análise, graças ao desenvolvimento de áreas como a arquitetura paisagística, planejamento de paisagens, conservação da natureza, além dos estudos geográficos e ecológicos. Ainda, para Guimarães:

[...] essa mudança de visão também estava vinculada a um processo de conscientização social diante dos problemas de degradação e poluição ambiental, crescimento populacional, conservação de recursos naturais e segurança global, impactos e riscos ambientais, entre outros. As novas concepções emergentes traziam não apenas mudanças nos processos de interpretação e valoração paisagística, como também o reconhecimento do meio ambiente como um sistema integrado, onde a paisagem é uma dimensão concreta espaço/temporal, envolvendo a integração estrutural e funcional da geosfera, biosfera, tecnosfera e psicosfera, em um complexo sistema de interações naturais e culturais $(2007$, p. 12).

Sendo assim, na Geografia do pós-guerra a Paisagem adquire fatores naturais e humanos, em uma análise integrada e sistêmica.

\section{A Bacia Hidrográfica do rio Fiúza e sua configuração paisagística no município de Panambi}

A área onde está inserido o município pertence à Bacia Hidrográfica do ljuí. Segundo o Plano de Saneamento Básico da Prefeitura Municipal de Panambi,

[...] esta Bacia situa-se a norte - noroeste do Rio Grande do Sul, entre as coordenadas $27045^{\prime}$ e 2615' de latitude sul e 5315' e 5645' de longitude oeste, abrangendo 20 municípios, com uma área de drenagem de 10.649,13 km² e com 337.249 habitantes. Seus principais formadores são os rios: Ijuizinho, Conceição, Potiribu, Caxambu, Faxinal, Fiúza e Palmeira. As atividades econômicas desta bacia, de maneira geral, estão ligadas ao setor primário, predominando as lavouras de soja. Esta bacia apresenta também potencialidade de geração de energia hidrelétrica, inventariada no "Inventário Hidrelétrico da Sub-bacia 
75"- Convênio SOPSH/DRH/CRH-RS-SEMC/CEEE - Outubro de 2000. O comitê de gerenciamento da Bacia Hidrográfica do Rio ljuí foi criado pelo Decreto Estadual no 40.916, de 30/07/2001(2008, p.13).

Segundo Leitzke (1990), a bacia do rio Fiúza cobre uma área de aproximadamente $190 \mathrm{~km}^{2}$, dos quais $150 \mathrm{~km}^{2}$ situam-se no município de Panambi e $40 \mathrm{~km}^{2}$ no município de Santa Bárbara do Sul.

Pelo registro cartográfico podem ser contados entre sangas e arroios 59 (cinquenta e nove) afluentes, sendo 27 (vinte e sete) à margem direita e 32 (trinta e dois) à margem esquerda. Entre os afluentes do Rio Fiúza destaca-se o Arroio do Moinho, a margem direita, pois seu curso interior corta a cidade de Panambi, e, em sua proximidade, viriam a surgir às primeiras indústrias que já marcaram a antiga Neu Württemberg (primeiro nome de Panambi).

A zona urbana da cidade é abastecida com água oriunda do sistema de abastecimento baseado no suprimento do manancial de superfície denominado Rio Fiúza, além de outros 4 (quatro) poços, sendo 1 (um) em atividade eos outros 3 (três) como reserva técnica.

O município de Panambi caracteriza-se por ser uma comunidade de médio porte com aproximadamente 11.600 economias, atendendo uma população urbana de 38.058 habitantes (IBGE/2010). O sistema existente consiste de captação junto ao Rio Fiúza, por meio de uma barragem de nível, estação de bombeamento e adutora, a qual interliga a captação com a Estação de Tratamento de Água (ETA) localizada dentro da zona urbana. Segundo Plano de Saneamento da Prefeitura Municipal de Panambi,

[...] a captação está localizada dentro do perímetro urbano do município, no rio Fiúza, e é realizada por meio de uma barragem de nível. O conjunto de bombas submersas, com vazão máxima de $140 \mathrm{l} / \mathrm{s}$. Existe também uma captação subterrânea que recalca por meio de uma tubulação de PVC DEFOFO, com 822 metros de comprimento e diâmetro igual a $150 \mathrm{~mm}$, para ETA (2008, p.5).

Em relação à paisagem onde foi construída esta estação, pode-se dizer que foi alterada pela ação antrópica, uma vez que havia necessidade de atender a população, pois a água é uma necessidade básica.

Nishijima (2009, p.42) diz que a "água é um recurso, assim como o solo e o ar ,indispensável no planeta. Após a era glacial formaram grandes rios que foram determinantes para o desenvolvimento das mais diversas civilizações, e tem sido assim através dos séculos". O autor continua dizendo que nosso corpo constitui aproximadamente $70 \%$ de água e dependemos dessa para a sobrevivência, transcendendo escolaridade, nível econômico, etc.

Assim, as ações antrópicas têm causado danos quantitativos e qualitativos às águas. Em relação aos danos quantitativos, os rios e mananciais têm diminuído a sua capacidade pelo assoreamento. Em relação ao fator qualitativo, também tem sido o decréscimo, causado principalmente pelos afluentes urbanos e industriais, agroquímicos e sedimentos, os quais são lançados ou carreados para o interior dos mananciais (Nishijima, 2008). 
A água apresenta os mais variados usos, segundo Tucci (2004) apud Nishijima (2008), esses usos são definidos em função das atividades econômicas, industriais e sociais da humanidade. Pode-se citar como usos múltiplos da água: abastecimento público, consumo industrial, matéria prima para a indústria, irrigação de cultivos agrícolas, recreação, dessedentação de animais, geração de energia elétrica, transporte, diluição de despejos e preservação da flora e fauna.

Conforme registro de Leitzke (1990, p.5), “o rio Fiúza como presença geográfica sempre deixou e vai continuar deixando marcado sua existência no povo de Panambi. Quem reside em Panambi, também conhece mais de perto ou longe o rio".

Em relação ao processo de ocupação do município, segundo Leitzkei (1991), a porção central da área urbana assenta-se nas terras que eram de Francisco Manual de Bairrosii. As razões para isto podem ter sido o fato de que era o local de residência deste senhor, e este local já funcionava como um ponto de convergência das rústicas estradas e trilhos, que ligavam os moradores da área entre os rios Fiúza e Palmeira. Também, neste local, havia uma infraestrutura, embora muito rudimentar e primitiva que oferecia recursos para as primeiras moradias. Deve-se levar em conta também, que a nova sede situava-se na saída da Colônia para Cruz Alta, para onde, evidentemente viria a existir a principal via de comunicação.

A Figura 2 - Traçado do município de Panambi/RS, retrata um pouco deste processo de ocupação. Este, por sua vez, apresenta um dos primeiros mapas traçados sobre Panambi, onde o rio Fiúza aparece em destaque, sendo que o centro urbano de Panambi foi demarcado no ano de 1901, pelo engenheiro Alexandre Ahrons, e, apresenta a margem direita do rio Fiúza, onde se localizava o Arroio do Moinho, o qual teve a área adquirida para a constituição da Sede do município.

A primeira denominação dada ao rio que atravessa a cidade de Panambi foi Arroio Corticeira. No decorrer dos tempos este rio recebeu o nome de Fiúza. A origem da denominação Fiúza deve-se ao dono de um estabelecimento comercial, também denominado no início do século XIX por bolicho iii, que se situava num local aproximadamente a 250 metros do passo", isso é, num ponto que hoje é o centro do bairro Vila Nova. Esse bolicho do senhor "Fiúza" tornou-se um ponto de referência, em virtude de sua proximidade com o rio. Os anos foram passando e o povo foi denominando aquele passo de Fiúza. Segundo Leitzke (1991), desde 1895 prevalece a atual denominação de rio Fiúza.

A partir de 1899 teve início a chegada da etnia alemã, vindo então a definir-se a colonização e a implantação do núcleo urbano de Panambi. Até 1910, este núcleo urbano localizava-se na área compreendida entre o Arroio do Moinho da Igreja Evangélica e a atual praça Engenheiro Walter Faulhaber. A partir de 1910 foram-se povoando lentamente os cursos das atuais ruas Sete de Setembro e General Osório. Passando por várias denominações, foi somente em 1944, que passou a denominar-se Panambi (LEITZKE, 1990).

O rio Fiúza no início da colonização alemã foi marcado de significado pela população. Várias pessoas praticavam o lazer de pesca e aprenderam a natação nas águas do rio Fiúza. Também existiram as margens deste rio um Balneário Público, onde se praticava o esporte de canoa (LEITZKE, 1990). A Figura 3 registra um dos momentos citados. 
Monografias Ambientais

(e-ISSN: 2236-1308)

REMOANFSM

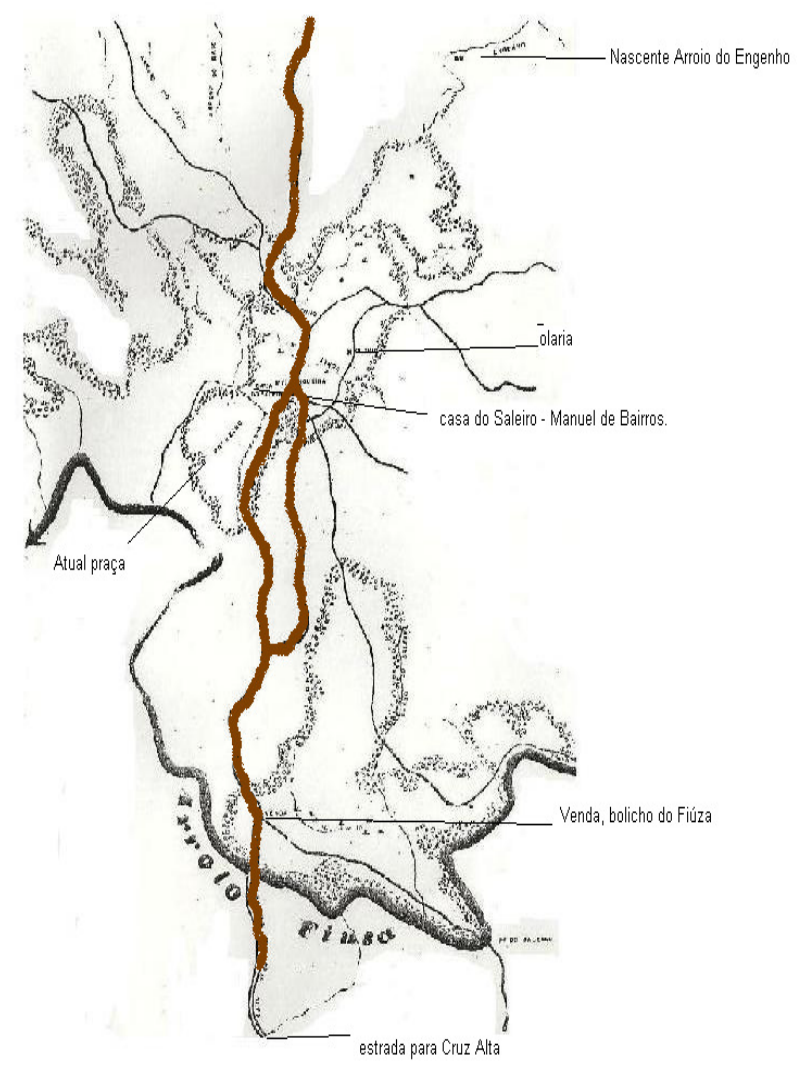

Figura 2: Mapa do traçado do município de Panambi/RS

Fonte: Museu e Arquivo Histórico Professor Hermann Wegermann, 2011

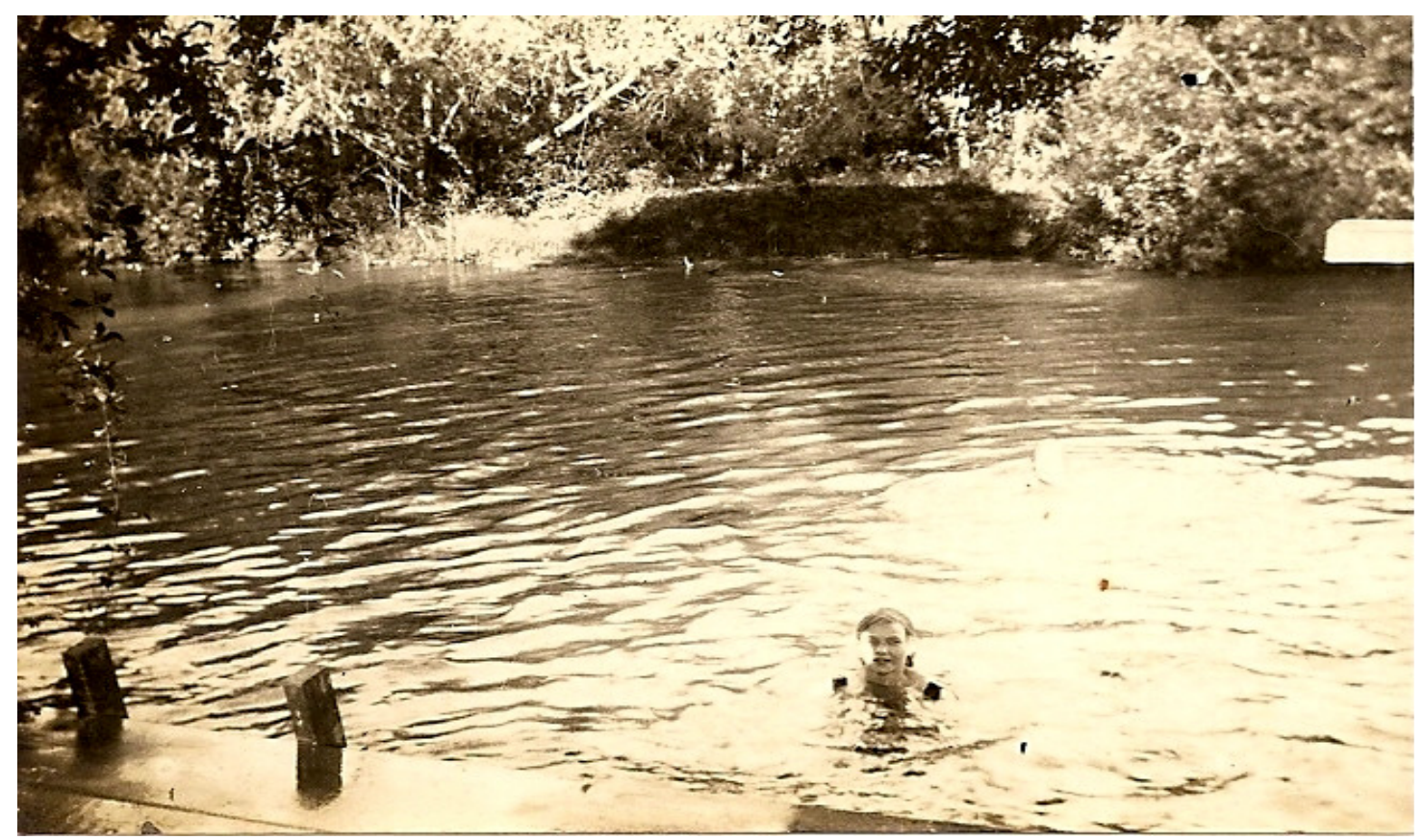

Figura 3 - Momentos de aulas de natação, década de 60. Fonte: Museu e Arquivo Histórico Professor Hermann Wegermann. 
Com a emancipação do município, a zona urbana cresce e avança em direção as áreas ribeirinhas do Rio Fiúza. São os seguintes bairros situados ao Sul do rio Fiúza: Pavão, Serrana, Alto Paraíso, Erica, São Jorge, Arco Iris, Piratini, Esperança e Jardim Paraguai. Os bairros situados na margem esquerda são: Timbará, Vila Nova, Parque do Moinho e o Centro da cidade. Na margem direita têm-se os bairros: Pavão, Serrana e Erica (LEITZKE, 1990).

Em relação a essa ocupação das áreas ribeirinhas, ressalta-se a afinidade entre a população do município e o rio, a qual estabelece suas relações de cotidianidade nas dimensões políticas, econômicas, sociais, entre outras. Por meio dessas relações, pode-se citar o Parque Municipal Rudolfo Arno Goldhardt. Este parque apresenta várias alterações antrópicas, as quais foram realizadas a fim de proporcionar aos panambienses uma área de lazer e ao mesmo tempo poder desfrutar da beleza do rio Fiúza, protegendo-o contra impactos negativos.

Com base nos princípios de preservação, o capítulo VI, Art. 20 do Plano Diretor do município (2006), trata do Patrimônio Histórico, Cultural, Artístico, Paisagístico e Arqueológico. Entre suas diretrizes, procura a valorização e restauração do patrimônio cultural, tornando-o reconhecido pelos cidadãos panambienses, garantindo que o patrimônio arquitetônico tenha usos compatíveis com a edificação, desenvolvendo o potencial turístico, de forma sustentável, baseado em seu patrimônio histórico, cultural, paisagístico e arqueológico.

No parque Municipal são realizadas as diferentes atividades que constam no Calendário de Eventos do Município de Panambi. Entre as atividades citam-se: Encontro de Corais, Cultos Ecumênicos, Baile do Chopp, Mostra de Trabalhos das diferentes Escolas, Feira do Livro, Feira do Artesanato, Congressos Nacionais e Internacionais, Encontro da terceira Idade etc. A área do parque pode ser visualizada através da Figura 4 - Parque Municipal Rudolfo Arno Goldhardt.

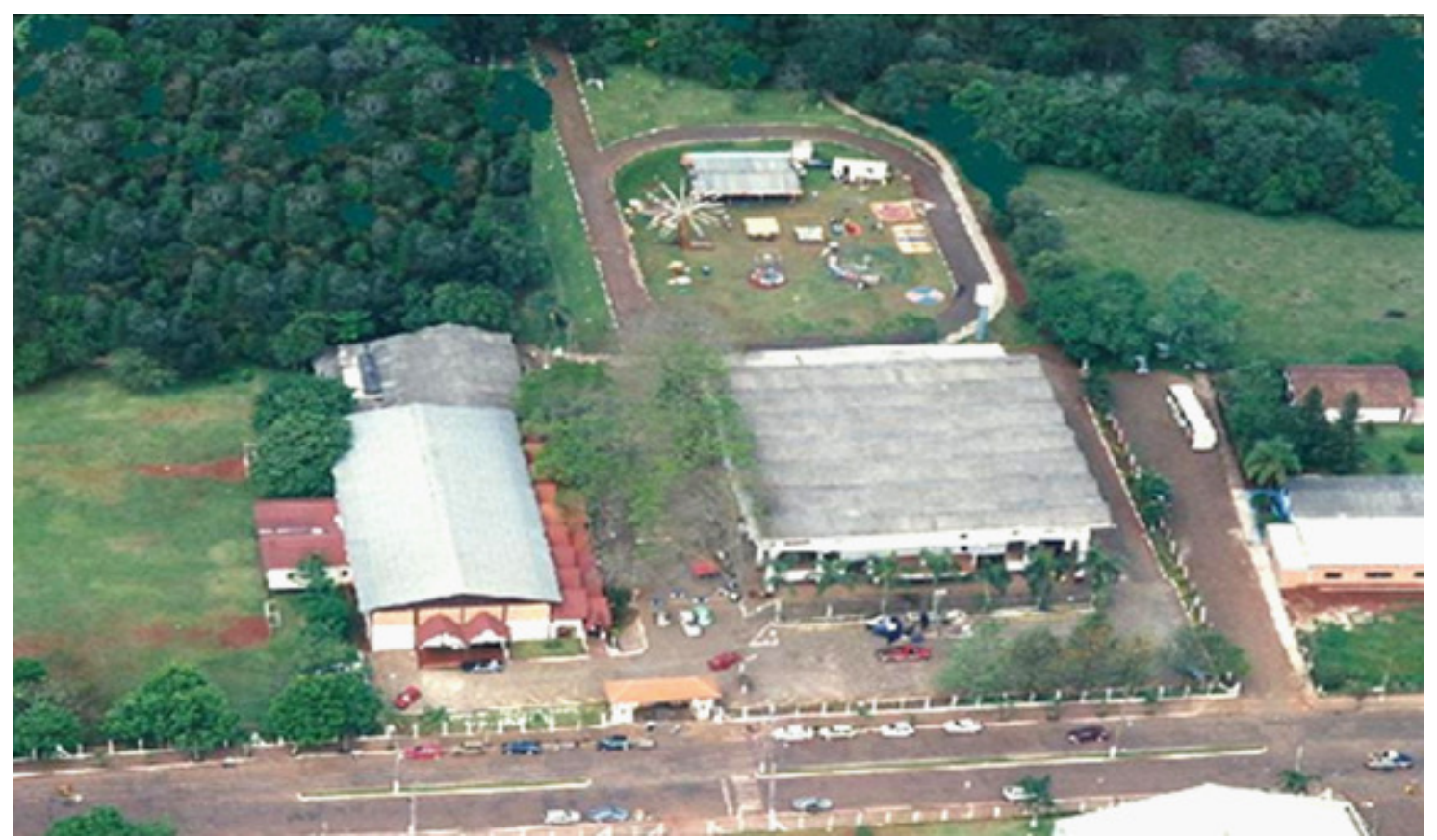

Figura 4 - Foto aérea do Parque Municipal Rudolfo Arno Goldhardt, Década de 90 Fonte: Museu e Arquivo Histórico Professor Hermann Wegermann, cedido pelo DESTUR, dez/2011. 
O Parque Municipal está estruturado às margens do rio Fiúza, por tratar-se de uma área imprópria para a ocupação urbana e também em obediência a legislação ambiental, que proibe a construção em áreas de preservação permanente. Este, por sua vez, abriga locais onde a paisagem ecológica - ou paisagem visual, percebida, como prefere o autor Andrés Muñoz-Pedreros - nativa está preservada, sendo adaptada as funções sociais da população. Neste lugar existem vários elementos constitutivos da paisagem. Entre eles, destacam-se os inseridos pelo homem, tais como as trilhas, os passeios, a academia ao ar livre, as áreas de convívio, um anfiteatro ao ar livre, parquinho, edificações de grupos étnicos, o museu e, por fim, um elemento natural a área, o rio Fiúza. Este rio é muito importante no contexto do Parque, pois além de fazer parte da paisagem, faz parte da história do município.

As trilhas ecológicas e passeios inseridos no ambiente pelo homem retratam uma preocupação em se manter o natural. Devem ser construídas de maneira a não agredir a paisagem ou causar o mínimo de impacto visual. Essas, por sua vez, são percursos onde pode-se realizar a interpretação ambiental do meio. A elaboração das trilhas ecológicas não visam somente a visualização da área ou informações biológicas, mas busca significados para obter conhecimentos, exercitar valores cognitivos, criar expectativas, suscitar questionamentos, despertar novos conhecimentos e fomentar a participação da comunidade.

Os percursos interpretativos podem ser temáticos, de descoberta ou de turismo. Os temáticos se realizam em função de um tema definido. Exemplo: fauna, flora, sons, texturas, cores, etc. Os percursos de descoberta e de turismo se realizam sem uma definição prévia de tema. O próprio grupo ao longo do caminho estabelece seus objetivos (MERCK, 2008).

Observando a Figura 5, visualiza-se o passeio construído ao longo da mata e sua proximidade com o Rio Fiúza. No entanto, para a construção deste passeio, utilizou-se de concreto, material agressivo ao meio, tornando-se um impacto a paisagem natural. Por trataremse de passeios próximos as margens do rio, permitem a população que nelas percorrem, desfrutar de sensações como sons, cheiros, formas e volumes promovidas pelo rio. Contudo, ao analisar sua proximidade com o rio, percebe-se que não há nenhuma proteção em relação a margem deste. Neste caso, qualquer acidente que vier a acontecer com o usuário, quem responderá pelo mesmo será o gestor do parque.

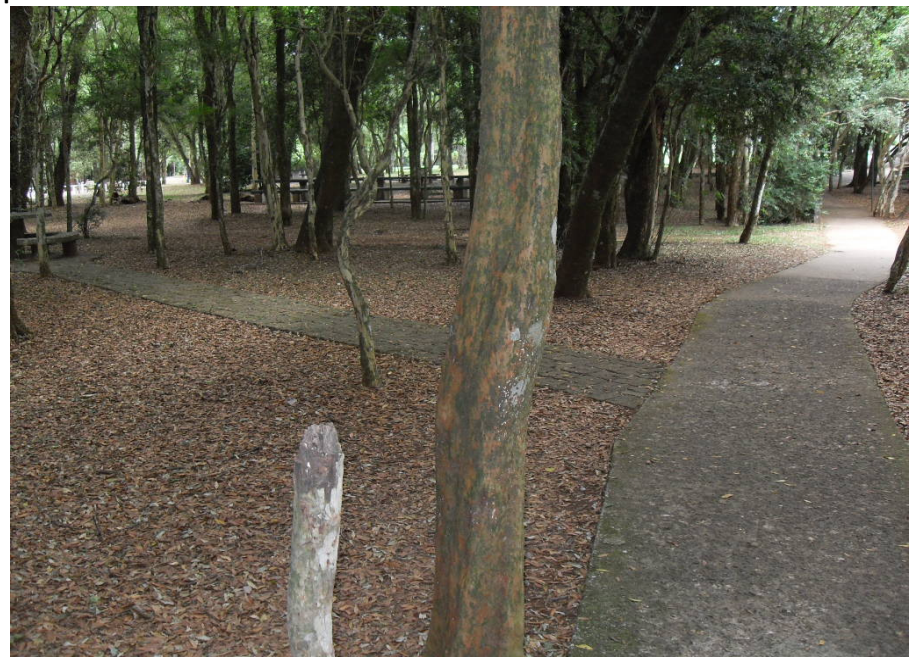

Figura 5 - Trilha ecológica interior ao Parque.

Fonte: Museu e Arquivo Histórico Professor Hermann Wegermann, dez/2011. 
Em relação aos diferentes ambientes criados conforme mostra a Figura 6, oferecem espaços de lazer e descanso, onde a população utiliza para reuniões e almoços familiares, principalmente em finais de semana. Da mesma forma que os passeios, são impactantes a paisagem, o que não ocorre com as trilhas, bem menos utilizadas no parque, mas que por possuirem caminhos lapidados naturalmente, se inserem sem grandes alterações a paisagem. Analisando a paisagem constatou-se a falta de mobiliários urbanos pelo parque, tais como lixeiras e placas de orientação, onde constem regras para utilização do Parque. Esta deficiência verificada na área tem ocasionado prejuízo ao meio ambiente, principalmente pela falta de conscientização ambiental da sociedade, que acaba depositando os lixos produzidos em locais inadequados - entre eles o rio - e não tem conhecimento das normas de utilização do parque.

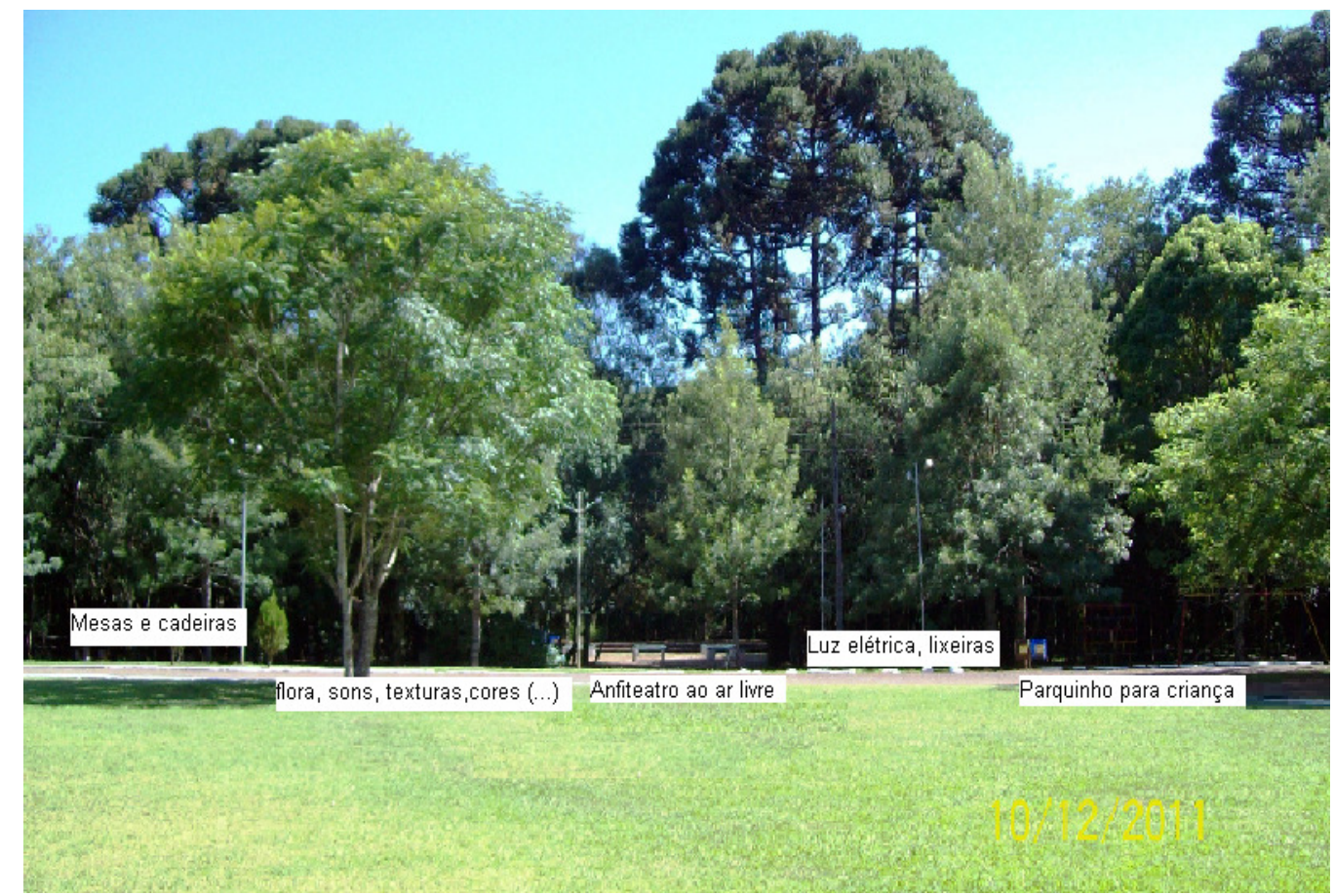

Figura 6 - Diferentes estruturas que o Parque municipal apresenta Fonte: Hempe, Cléa. 10.12.2011.

No parque também foram construídas edificações que representam réplicas de casas de várias etnias, conforme mostra a figura 7- Réplicas de casas de Etnias: gaúcha, portuguesa, holandesa etc. 


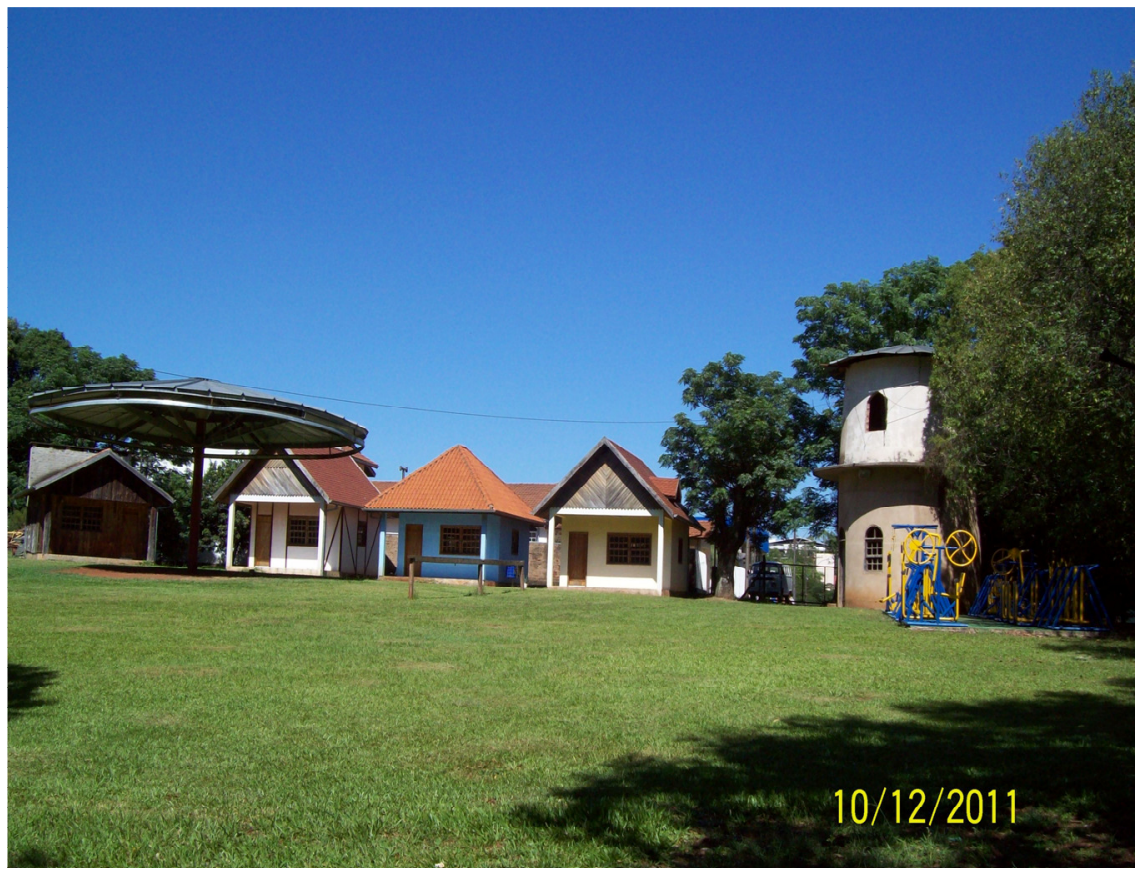

Figura 7 - Estilos arquitetônicos de diferentes etnias. Fonte: Hempe, Cléa. 10.12.2011.

Estas edificações apresentam algumas irregularidades, pois ao realizarem-se as obras de construção, não foram levadas em consideração todas as características do edifício original. Notase que foram colocados elementos e materiais que não correspondem a sua originalidade.

Outras edificações de destaque no parque são o ginásio de esportes e o salão de festas. Estas possuem estilos arquitetônicos diferentes e, por estarem localizadas próximas, acabam por impactar a paisagem do Parque. Mas, mesmo sendo impactantes do ponto de vista arquitetônico do local, ambas exercem grande atração de públicos, tanto locais como visitantes.

O ginásio de esportes abriga, em seu segundo pavimento, o Museu e Arquivo Histórico Professor Hermann Wegermann e tem um estilo contemporâneo de construção. Neste, por sua vez, podem ser apontadas outras irregularidades, tais como a ausência de acessibilidade, que contradiz a lei que prevê que todos os espaços públicos, sejam adaptados.

Verificou-se ainda através da leitura dos referenciais teóricos e do relato de funcionário do museu, que o mesmo não possui trabalhos direcionados ao estudo do rio Fiúza e seu entorno, mesmo este estando localizado dentro de um parque urbano que tem o rio como seu principal atrativo.

\section{METODOLOGIA}

Para elaborar o presente artigo utilizou-se da pesquisa bibliográfica e de campo. Primeiramente fez-se um levantamento com busca em livros e materiais disponibilizados no decorrer da disciplina. Após entrou-se em contato com o Museu e Arquivo Histórico Professor Hermann Wegermann de Panambi/RS.Os colaboradores desse Museu disponibilizaram vários materiais por e-mail, estes constavam de levantamento de dados qualitativos e quantitativos, 
imagens relacionadas ao objeto de estudo, os quais foram sistematização por temas afins e, por fim elaborou-se o artigo científico de forma coletiva.

\section{RESULTADOS E DISCUSSÕES}

Analisar uma região, juntamente com as características populacionais, paisagistas é sem dúvida se inserir no processo, é estar como coadjuvante das transformações alavancadas. Assim quando cotejados conceitos e aspectos sobre a conjuntura cultural do município de Panambi, mais necessariamente na congruência do traçado da bacia hidrográfica do rio Fiúza, é voltar ao tempo em que o rio tinha outro significado. Um sentido de sobrevivência, de utilidades decorrentes da relação ambígua entre o homem e os elementos naturais disponíveis.

Contudo, o processo de colonização ocorrido na área em questão, juntamente com outros fatores provindos deste processo como a urbanização, crescimento populacional, êxodo rural, fez com que os elementos naturais passassem a ter outro significado para a população local.

É imprescindível ter a clareza que quando tratados os termos de alteração paisagística e utilização de recursos naturais torna-se necessário ter em mente (e esse foi um dos objetivos do trabalho em questão) que os mesmos não são meramente utilitários aos humanos e sim pertencem a um meio que tem aspirações, que está intrinsecamente interligado, organizado, que é sensitível e que é vital que esteja em equilíbrio.

Dessa forma os objetivos propostos, foram alcançados na medida em que foi feita a análise e correlação da paisagem integrada. É necessário termos a consciência que qualquer estudo deve comportar questões que afetam nosso cotidiano, que melhorem e nos tragam parâmetros nas diversas abordagens, e que, acima de tudo, nos deixem cada vez mais preparados para discutir num mundo complexo, onde os interesses pessoais são colocados em questão e que muitas vezes, são empecilhos na engrenagem da instrumentalização da modernidade e do planejamento ambiental.

\section{REFERÊNCIAS}

AGUIAR, A. E. X.; OLIVEIRA, I. P.; CRUZ, L. B. Análise dos impactos ambientais e níveis de conservação da lagoa de Precabura e sua bacia hidrográfica. In: Simpósio Nacional de Geomorfologia - SINAGEO, 8, 2008. p-74.

BONAMETTI, J. H. O impacto da ação do IPPUC na transformação da paisagem urbana de Curitiba a partir da área central. Dissertação (Mestrado em arquitetura e urbanismo) Escola de Engenharia de São Carlos, Universidade de São Paulo. São Carlos: 2000.

CUNHA, S. B. Canais fluviais e a questão ambiental. In: CUNHA, S. B.; GUERRA, J. A. T. (Org.). A questão ambiental: diferentes abordagens. Rio de Janeiro: Bertrand Brasil, 2007.

EMERY, O. RHEINGANTZ, P. A. Para evitar a construção de uma paisagem sonora autista, é preciso saber ouvir a arquitetura. Disponível em: <http://www.vitruvius.com.br/revistas/read/arquitextos/02.015/861>. Acesso em: 08 dez/2011.

FIGURAS 2 a 5. Disponibilizadas pelo Museu e Arquivo Histórico Professor Hermann Wegermann através de email em 08/12/2011. 
FIGURAS 6 e 7. HEMPE, Cléa. Trabalho de Campo: 09/12/2011. 10 horas da manhã.

GORSKI, M. C. B. Rios e Cidades: Ruptura e Reconciliação (dissertação de mestrado). São Paulo, 2008.

GUIMARÃES. S. T. de L. Paisagens: aprendizados mediantes as experiências. Um ensaio sobre interpretação e valoração da paisagem. Tese (livre docência). Universidade Estadual Paulista, Rio Claro, 2007.

HOLANDA, S. B. de. Caminhos e Fronteiras. 3. a ed. São Paulo: Companhia das Letras, 2001.

IBGE. Cidades. Censo de 2010. Disponível em:< http://www.ibge.gov.br/cidadesat/topwindow.htm?1>. Acesso em: 08 de dez 2011.

LEITZKE. Eugen. Jornal Notícia llustrada. Coluna do Arquivo Histórico Panambi. In Museu e Arquivo Histórico Professor Hermann Wegermann. Panambi/RS.

1970 a 1993.

. Jornal Notícia llustrada, 1991. Coluna do Arquivo Histórico Panambi. In Museu e Arquivo Histórico Professor Hermann Wegermann. Panambi/RS.

Panambi.

. Jornal Notícia llustrada, 1990. Coluna do Arquivo Histórico Panambi

Panambi. In Museu e Arquivo Histórico Professor Hermann Wegermann. Panambi/RS.

MERCK, A. M. T. Professora Pesquisadora, Conteudista. Disciplina interdisciplinariedade. Curso de Especialização Educação Ambiental. Trilhas Ecológicas, 2008.

NISHIJIMA. Toshio. Professor Pesquisador e Conteudista. Curso de Especialização em Educação Ambiental. Disciplina Água e Solo, 2008.

OSEKI, J. H. A Fluvialidade no Rio Pinheiros: Um Projeto de Estudo. Revista do Programa de Arquitetura e Urbanismo da FAU-USP, São Paulo, 2000.

PANAMBI. Lei do Plano Diretor participativo de Desenvolvimento Municipal de Panambi - RS, Jun de 2006.

. Prefeitura Municipal. Plano de Saneamento Básico, 2008.

RADOLL, G. R. Transformação da paisagem e do espaço Público em uma sub-bacia do Embu das artes. Universidade de São Paulo / Faculdade de Arquitetura e Urbanismo, 2009.

SANDEVILLE JR, E. Paisagem. Paisagem e Ambiente. Pôster. São Paulo, v. 20, p. 47-60, 2005. 
VEROCAI, I. Dicionário Básico de Meio Ambiente. Fundação Estadual de Engenharia do Meio Ambiente. Serviço de Comunicação da Petrobrás. Rio de Janeiro, 1990.

' LEITZKE. Eugen. Organizador do Museu e Arquivo Histórico da Colonização de Panambi, de 1968 a 1993. Primeiramente funcionou no Colégio Evangélico Panambi (CEP). Em quatro décadas de existência, inúmeros objetos e documentos foram acrescentados ao acervo, entre os quais se destacam: uma réplica da Catedral de Ulm (Alemanha); um grupo de urnas funerárias indígenas; os documentos da Empresa que promoveu a colonização de Panambi; uma coleção de borboletas com cerca de 1500 exemplares; os livros da extinta Sociedade de Leitura Hermann Faulhaber.

ii Francisco Manuel de Bairros, morador da Colônia Neu Württemberg, o qual vendeu suas terras para a Colonizadora. No Museu e Arquivo Histórico consta o seguinte “... lavra de escritura, feita em 13 de julho de 1.899 “...uma posse de matos, terras de cultura, engenho de serrar madeiras e mais benfeitorias, situada na Serra Geral de ljuí, no lugar denominado Salina, no quarto distrito deste município".

iii No sul, bolicho é uma pequena casa de comércio, é um local aonde o viajante chega para retemperar com convívio humano o isolamento de uma longa jornada. Se, ao final do dia, o bolicheiro não vender nada, mas tiver tido bastante convívio humano, é um homem feliz.

iv Passo, significava um lugar onde havia um rio, porém não havia ponte, as pessoas passavam por dentro d'água. 